\title{
Washington, DC's Lottery-Rotation System for Food Trucks: A Step in the Right Direction
}

\author{
By Clint Trocchio and Paul J. Miller
}

DC officials enacted a Mobile Roadway Vending lottery in December 2013 that allocated street-metered parking spaces to the 250 food trucks operating throughout the District. Its creation was predicated on the belief among DC administrators that food trucks inject vibrancy into the urban environment and create job opportunities. Across America, though, expert regulators' and political leaders' opinions vary on how food trucks should be managed to accommodate the concerns of stakeholders who share limited street parking. By comparing DC's lottery-rotation system to pure lottery and auction systems, we reveal the difficult-to-attain middle ground sought by officials who are caught between allocating parking through a lottery or through an auction sale that can possibly favor a wealthy minority. We acknowledge the benefits found in the District's decision to create a policy that allows vendors the flexibility to roam for available street parking in some areas and to compete in a semirandom lottery for guaranteed parking in other areas. We suggest the lottery-rotation system's major inefficiencies would be largely remedied by a secondary market allowing vendors autonomy to make asneeded parking trades. We conclude by asserting that, while the lottery-rotation system is economically inefficient, it is part of a broader, reasonable first effort that strikes an economic and political equilibrium in a dynamic industry and regulatory landscape.

\section{Food Trucks and the Use of Public Commons in Washington, DC}

America's growing food truck industry commands attention not only for its burgeoning consumer appeal but also for its use of public commons to generate private profits. City governments must balance the positive and negative externalities that this dynamic marketplace presents with policies aimed at effective and efficient allocation of common resources. Recent debate over Washington, $\mathrm{DC}$ 's mobile vending regulations follows a nationwide pattern of city government policy changes meant to accommodate the interests of small business entrepreneurs.

In this article, we analyze the changes to Washington, DC's streetside vending rules that emerged from this debate. To do so, we first review the District's public problem in managing food truck activity from the perspective of economic theory. In this discussion, those positive characteristics of the mobile vending marketplace that DC officials sought to preserve in crafting the policy are also described. We then outline the details of the policy option that the District chose, a lottery-rotation system that grants public parking to mobile food truck vendors. In doing so, we consider the policy within the context of two prominent policy alternatives for allocating parking-a 
pure lottery and a pure auction-contrasting these approaches' strengths and weaknesses to those associated with the District's lottery-rotation approach. We argue that while Washington, DC's new mobile vending laws are a substantial upgrade relative to the previous regime, introducing a secondary trading market will further improve it by increasing parking utilization. Finally, we indicate why introducing prorated lottery fees, a currently discussed alternative to increase utilization, should be avoided. Allowing for a secondary market would address the inefficiencies in the lottery's allocation approach while supporting the policy's necessary political compromise in combining the lottery-rotation system with food truck street roaming.

\section{Background on Washington, DC's Food Trucks}

America has a growing demand for food truck cuisine. The National Restaurant Association estimates that in 2012 food trucks generated $\$ 650$ million in revenue-about 1 percent of nationwide restaurant sales (Intuit 2012). By 2017 this level is expected to rise to nearly 4 percent, or $\$ 2.7$ billion, of total restaurant revenues (Intuit 2012). Washington, DC's local food truck movement is part of that rapid growth, with its vendors representing the breadth of cuisine options available.

Recognizing the urban energy these entrepreneurial businesses create, as of September 2014, Department of Consumer and Regulatory Affairs (DCRA) officials have granted approximately 300 mobile vending permits ("Class A Licenses") to food truck operators (DCRA 2014). Moreover, according to Vincent Parker, DCRA's vending manager, approximately 150 of Washington, DC's food trucks operate daily in the District (pers. comm.). Nearly one-third of these vendors belong to the largest local food truck advocacy organization in the area: the District of Columbia, Maryland, and Virginia Food Truck Association (DMV FTA). Led by a group of professionals with years of mobile vending experience, the DMV FTA was formed in 2010 to address a proposed moratorium on DC food trucks (DMV FTA 2014). The group continues to actively promote the local food truck industry's interests and helps its members positively engage the community, say founding members Doug Povich and Che RuddellTabisola (DMV FTA 2014; Povich and Ruddell-Tabisola, pers. comm.).

Consumer demand propels the food truck market and motivates trucks to operate in the District during lunchtime. Trucks tend to travel in groups to attract more consumer attention; they relocate based on relative demand and to build new clientele bases around the District (Trocchio et al. 2014). This gives food trucks an advantage over brick-andmortar restaurants, which can suffer from unbalanced consumer demand that varies by time and location. Food trucks stabilize their revenue stream by adjusting to seasonal trends and focusing on where customers are concentrated. All a truck needs to do is find a place to park.

Like other major cities, finding parking is no small issue in Washington, DC. Street parking in the District is limited in supply and high in demand. Washington, DC's Department of Transportation (DDOT) manages approximately 17,000 metered public parking spaces throughout the District, some of which are in the busiest commercial districts and command "premium demand zone" prices of $\$ 2.00$ per hour (DDOT 2013). Yet, even in those zones, prices remain well below their market values and below 
what is charged in most other similarly situated cities ("Americans" 2015).

As with many cities forced to find additional cash flows when faced with rising budget costs, fines can be a major source of municipal revenue, and Washington, DC, is no exception. The District is widely recognized for its aggressive parking enforcement and collection measures, earning notoriety in 2011 for fining on average $\$ 159$ dollars per citizen-more than the cities of New York and Los Angeles combined (Neu 2013). In fiscal year 2013, Washington, DC, issued over 1.7 million parking tickets, totaling over $\$ 82$ million in revenue for the District (Blanche 2014).

Before Washington, DC, established its current mobile vending regulations, which include an online lottery system that debuted in December 2013, many food truck owners parked their private vehicles illegally on the street-early in the morning or even the night prior-to hold spaces for their trucks. For example, Robert Estep, a multi-truck owner and operator, commented that parking in front of Washington, DC's highly-trafficked Metro Center Station supplied his businesses with enough revenue to validate the nearly $\$ 1,000$ per month in parking fines his trucks racked up while operating in the area before the lottery-rotation system began (pers. comm.). Regulating the behavior of DC's mobile vendors has challenged the city's leadership for over 100 years.

Washington, DC's vending history dates back to 1887 when Congress first gave the District power to regulate street vending. In 1974, "the vending program had fallen into disarray" according to District officials (DC PSCA 2009), and by 1998, it was clear that more effective program oversight and management were required (DC BCRA 2013). DCRA and DDOT leaders were concerned that the growing popularity of food trucks was causing vendors to fight over parking spots, thus creating pedestrian hazards. Other activities, including vendors dumping kitchen by-product waste into street gutters and stuffing sidewalk trash bins with food truck and consumer generated waste, created street-side cleanliness issues (Parker, pers. comm.). Borrowing from microeconomic theory, the District government viewed these effects as negative externalities, or costs imposed on the community stemming from the unregulated food truck market. While consumers do not necessarily pay higher lunch prices to account for the disputes between vendors or their wastewater disposal onto the street, District officials (and taxpayers more broadly) bear a cost for the behavior, taking the form of increased calls for police action and DCRA enforcement fines to manage parking disputes and trash collection.

\section{Government Response}

Instead of eliminating the unwanted side effects of food truck operations by severely restricting mobile vending, DC officials demonstrated an interest in preserving food trucks' role as an urban centerpiece of small business growth through a more informed regulatory response (Farrell 2013). After several stakeholder debates, the DC Council decided that it would attempt to mitigate the negative externalities related to parking disputes while, at the same time, maintaining the breadth of food truck activity.

Yet, the regulations the District initially proposed were restrictive, prohibiting sidewalk vending within the Central Business Vending Zone in places with adjacent, unobstructed sidewalks less than 10 feet wide (Carman 2012a). Food truck advocates 
created a map highlighting those streets proposed for closure to food truck vending (Johnson 2013). These advocates, including the DMV FTA, suggested that the proposed 10-foot standard would render noncompliant eight of the 10 most popular food truck destinations in downtown Washington, DC (Carman 2012b). As a result, the mobile vending industry faced the prospect of radical change. In response, on May 10, 2013, the DC Council Committee on Business, Consumer, and Regulatory Affairs (BCRA) heard testimony from food truck business leaders, restaurant association lobbyists, political scientists, and economists who described the market and the political forces that influence food trucks. After considering the testimony and reviewing the feedback collected during the public comment period, the DC Council amended the 10-foot proposal to six feet in its final rule, thus ensuring that many of these food truck hotspots remained legal.

Still, the compromise to lessen the required Mobile Roadway Vending (MRV) sidewalk clearance was part of a larger policy discussion that the Council was facilitating. The hearing became a forum for policy experts to analyze and voice opinions about two alternative policies-a pure lottery and an auction - that were seen as the primary options to allocate parking to food trucks (Parker, pers. comm.). A variant, which included elements of these alternatives, would also be part of the DC Council's final rule several months later.

\section{Washington, DC's Compromise: A Lottery-Rotation System}

The District's final decision to allocate public parking to food trucks took the form of a hybrid plan that combined guaranteed parking via a lottery system with ad hoc availabil- ity via a flexible roaming policy. To grant vendors guaranteed parking, DCRA first partnered with DDOT to create MRV zones in the downtown areas that were consistently attracting the greatest amount of enforcement action. Some of these zones are located within the city's Central Vending Zone (DCRA 2015a).

DCRA then began allocating parking spots within these newly created MRV zones through a lotteryrotation system. The first food truck proposal map depicts the locations of 15 mobile vending locations in the city ("Food Truck" 2013). To help consolidate and limit roaming on city streets within the Central Vending Zone, the District enacted limits on roaming near MRV zone parking, and regulated all other non-MRV zone parking within the District in accordance with standing meter rates and availabilities. Thus, for a truck to vend within the District, it could: (1) participate in the lottery to earn parking within an MRV zone; or, if unsuccessful in the lottery, (2) roam within the District boundaries in accordance with the limits prescribed in DC Municipal Regulations Title 24, Subsection 534 and 535 . This new system became law on October 1, 2013, and the first lottery occurred in December of that year.

As a result of this system, DCRA now requires food trucks to purchase multiple licenses. Table 1 lists the principal DCRA vending fees, which include charges for a Class A Vending License, a Vendor Employee ID, and a Mobile Roadway Vending Site Permit (VSP). A vendor may also participate in the lottery-rotation system for guaranteed parking in select MRV zones for an additional \$175 per month (a \$150 designated MRV Location Site Permit (lottery) plus a \$25 MRV Location Lottery Entry Fee). As part of the October 2013 
Table 1: Vending Fees

\begin{tabular}{|c|c|c|}
\hline License & Price & Term \\
\hline Class A Vending License & $\$ 476$ & 2 Years \\
\hline Vendor Employee ID & $\$ 55$ & 2 Years \\
\hline Site Permit: Mobile Roadway Vending (VSP) & $\$ 600$ & 2 Years \\
\hline Designated MRV Location Site Permit (lottery) & $\$ 150$ & Monthly \\
\hline MRV Location Lottery Entry Fee & $\$ 25$ & Monthly \\
\hline
\end{tabular}

Source: DCRA (2015b).

revisions to Washington, DC's vending laws, DDOT and DCRA officials collaborated to create $23 \mathrm{MRV}$ zones throughout the District. Only some of these MRV zones are entered into each month's lottery. The lottery-rotation mechanism requires vendors to enter an online website portal using their VSP number. Once there, they select and order the available MRV zones in the next monthly lottery based on their preferences before submitting their choices. In October 2014, the lottery's nine selected MRV zones contained 104 parking spots.
After food trucks submit their monthly preferences online, a drawing is held. Though the full lottery algorithm revealing how vendors are selected is the proprietary knowledge of the DCRA, Tables 2 and 3, which DCRA regulators shared with us, demonstrate the results of one potential hypothetical drawing. In this example, there are eight available MRV zones (theoretically consisting of one parking spot each), and nine food truck entrants. Table 2 shows that only the first Monday of each week's assignments are randomized;

\section{Table 2: Month \#1 - MRV Lottery Order of Preference}

(Model based on 8 available MRV spaces and 9 entrants)

\begin{tabular}{|c|c|c|c|c|c|}
\hline $\begin{array}{c}\text { Order of } \\
\text { Preference }\end{array}$ & Monday & Tuesday & Wednesday & Thursday & Friday \\
\hline 1 & A & I & H & G & F \\
\hline 2 & B & A & I & H & G \\
\hline 3 & C & B & A & I & H \\
\hline 4 & D & C & B & A & I \\
\hline 5 & E & D & C & B & A \\
\hline 6 & F & E & D & C & B \\
\hline 7 & G & F & E & D & C \\
\hline 8 & H & G & F & E & D \\
\hline OFF & $\underline{I}$ & $\underline{H}$ & $\underline{G}$ & $\underline{F}$ & $\underline{E}$ \\
\hline
\end{tabular}

Source: Parker (2013). 
food truck " $A$ " earns its top preference on Monday, " $\mathrm{B}$ " earns its second preference on Monday, and so forth. Thereafter, food trucks' preferences maintain a predetermined order and are "rotated" throughout the remainder of each week in the month.

If the number of vendors that participate in the lottery exceeds the parking spots contained within the available MRV zones, some food trucks receive no daily MRV assignment, a condition DCRA labels "off" in Table 2. No food truck is allotted a second day of the week without an MRV assignment until all other food trucks have one day without an MRV assignment. If a food truck receives one or two days without assignment in December, it will be prioritized to potentially have fewer days without assignment in January, assuming that the number of parking spots and entrants remains the same.

Table 3 shows how DCRA limits the number of days a truck is without assignment in consecutive months. To create greater equity in month \#2 for those trucks having a day "off" in month \#1, DCRA creates different priority entrant groupingsdenoted by the bold-lettered trucks and the shaded trucks, all having participated in month \#1's lottery. While holding the conditions from Table 2 constant (eight available MRV zones, nine entrants), Table 3 depicts how DCRA arranges the next month's rotational outcome. We see that the boldlettered food trucks (E, F, G, H, and I), having had one day off in month \#1 (Table 2), are now prioritized ahead of the shaded trucks (A, B, C, and $D$ ). To ensure month-to-month equity in this example, DCRA officials separated food trucks into two distinct and differently prioritized groups, and then randomized trucks within these groups to create the next month's rotation assignments. It is with this same strategy of "priority grouping" that DCRA ensures new entrants to the monthly lottery start in a lower preference group and are more likely to earn a day without assignment (Parker 2013). In addition to this example of process intervention, officials can-and do-manipulate the

Table 3: Month \# 2 - MRV Lottery Order of Preference

(Model based on 8 available MRV spaces and 9 entrants)

\begin{tabular}{|c|c|c|c|c|c|}
\hline $\begin{array}{c}\text { Order of } \\
\text { Preference }\end{array}$ & Monday & Tuesday & Wednesday & Thursday & Friday \\
\hline 1 & G & A & B & C & D \\
\hline 2 & F & G & A & B & C \\
\hline 3 & E & F & G & A & B \\
\hline 4 & I & E & F & G & A \\
\hline 5 & H & I & E & F & G \\
\hline 6 & D & H & I & E & F \\
\hline 7 & C & D & H & I & E \\
\hline 8 & B & C & D & H & I \\
\hline OFF & $\underline{A}$ & $\underline{B}$ & $\underline{C}$ & $\underline{D}$ & $\underline{H}$ \\
\hline
\end{tabular}

Source: Parker (2013). 
algorithm's results to accommodate discrepancies beyond the vendors' control (for example, lost parking assignments due to DDOT construction activity).

The lottery application period begins 40 days prior to the beginning of monthly vending, with the drawing occurring when the application period ends 10 days later. Following the drawing, vendors can view their MRV zone assignments and, if they like the result, pay an additional $\$ 150$ nonrefundable fee to accept it. This payment also guarantees month-long street parking from 10:30 a.m. to 2:30 p.m., Monday through Friday, at any parking meter within the assigned MRV zone. All other vehicles are prohibited from parking in these zones during this time period. Food trucks may not arrive earlier than 10:30 a.m., and they may not stay beyond 2:30 p.m.

A food truck operating outside of a designated MRV location-a "roamer" - must vend in a legal parking space, pay all parking meter fees, obey all posted parking time restrictions, and remain 200 feet away from MRV zones. Assuming there are 22 working days per month, and parking costs $\$ 2$ per hour, these roamers will pay $\$ 176$ per month for premium demand parking-only $\$ 1$ more than the nonrefundable fees associated with lottery participation.

On December 1, 2013, Washington, DC's first monthly lottery rotation attracted 120 out of the approximately 250 licensed food trucks, and each truck paid $\$ 25$ to participate. As Table 4 shows, close to 100 parking spots were available. After the drawing, the results were posted, and 116 food trucks valued their assignments enough to pay the additional $\$ 150$ to accept them.

\section{Policy Analysis and Recommenda- tions}

A first consideration in analyzing the design of Washington, $\mathrm{DC}^{\prime} \mathrm{s}$ lottery-rotation system is to recognize that the underlying problem that it attempts to solve is essentially a common pool resource problem. A common pool resource is one in which people cannot be excluded from using it but those that do in some way limit others from simultaneously using the full resource as well. In other words,

Table 4: December 2013 Lottery Rotation Locations and Spaces

\begin{tabular}{|c|c|}
\hline Designated MRV Location & Number of Spaces \\
\hline Farragut Square & 17 \\
\hline Franklin Square & 12 \\
\hline George Washington University & 3 \\
\hline L'Enfant Plaza & 18 \\
\hline Navy Yard/Capitol Riverfront & 8 \\
\hline Metro Center & 13 \\
\hline Union Station & 14 \\
\hline Virginia Avenue (State Dept.) & 10 \\
\hline Total & $\mathbf{9 5}$ \\
\hline
\end{tabular}

Source: Parker (2013). 
common pool resources are considered non-excludable and rivalrous. Examples include the timber located in forests and the biomass swimming in fishing grounds. Economic theory predicts that because common pool resources are non-excludable but rivalrous, they will be overconsumed or otherwise degraded as a result. In effect, use of the resource creates negative externalities because it simultaneously limits its use by others. In this example, erosion from deforestation and the decimation of certain pelagic species of fish are negative externalities. Without users considering the devaluation or overuse of these common pool resources (which they will not if they are acting in their self-interest), the diminished condition of the resource may become unrecoverable, which is why the term "tragedy of the commons" is often used to describe such situations (Hardin 1968).

In the days before DC's new lottery-rotation system, the overuse or improper use of public parking by DC's food trucks exemplified characteristics of a commons problem. Given the nominal prices assigned to parking spaces, the spaces themselves became essentially non-excludable.

Moreover, food trucks could not keep other food trucks from using a parking space, unless they occupied it themselves. Of course, once a truck did occupy a space, others could not simultaneously use that same space, making parking rivalrous. Conflicts over parking oftentimes led to fights and resultant police action. In addition, vendors often simply dumped kitchen waste into street gutters and completely filled sidewalk waste bins with their trash and leftover scraps. Not fully borne by the truck vendors themselves, these negative externalities imposed costs on the DC community more broadly.
A standard approach to managing a commons problem is to assign ownership over the resource, otherwise known as assigning property rights. By making individuals or groups of individuals owners of the resource or different parts of it (however that is accomplished), there is now sufficient incentive to manage the commons such that it is not depleted. After all, if these individuals do deplete or degrade the resource, they are the ones who are hurt by their actions.

One way to assign property rights to street parking is through the installment of parking meters. By paying for parking at an open meter, a food truck-or any vehicle for that matter-earns the privilege to occupy a street space for a designated period of time. However, parking rates in the District are uncharacteristically low even relative to other similar large U.S. cities. Because local politics makes enforcing outdated regulations and raising these parking fees infeasible, the price for public parking is not a strong enough sanction to make the resource effectively excludable. Furthermore, charging a fixed price instead of a demand-responsive price for downtown parking assumes that food truck vendors equally value all downtown parking spots, which is not the case. According to University of Arkansas political science professor John Gaber, the value of urban real estate-be it a parking spot or a surveyed lot-is not transitive (pers. comm.). Not all locations are equally valuable. Some locations are considered more valuable than others, and, not surprisingly, oftentimes the parking spaces most valued are the ones subject to the largest negative externalities imposed through the activities of food trucks.

One way to manage the commons problem associated with food 
truck parking, without addressing the more difficult task of changing the city's parking price scheme, is to establish food truck-only parking zones. This seems a step closer to assigning property rights, but in DC's new policy, food trucks are not assigned to specific parking meters within multi-spot MRV zones; a truck may choose any parking spot within the zone assigned. Some spots within these zones, by virtue of their proximity to a Metro subway escalator, for example, attract more business opportunity for vendors. Because of the enormous effort and cost District officials would assume if the new policy required officials to specifically assign private rights to hundreds of spots to trucks on a monthly basis, officials considered two broad ways to assign parking rights to the District's food trucks in MRV zones at large: an auction and a lottery.

An auction is a public sale of an item to the highest bidder. As a method of exchange, auctions have a reputation for revealing a buyer's private value for an item (Easley and Kleinberg 2010; CBO 1992). A secondprice sealed bid auction, or Vickrey auction, is considered superior among auctions with respect to administrative ease and timeliness because it generally discourages speculative entries. Unlike traditional auctions, which incentivize participants to guess what others will bid and submit slightly higher bids, a Vickrey auction more effectively reveals market information than a traditional auction by demonstrating participants' true reservation prices and opportunity costs. While participants secretly place bids, and the highest bidder wins, the second-highest bid is the winning price in a Vickrey auction, which is the mechanism that encourages participants to bid their true valuations. Still, both methods would certainly contribute greater parking revenue streams for the city compared to the current method of charging fixed-rate pricing at the street.

Regardless of the type chosen by District officials to assign food truck parking, allocating parking through an auction was deemed not compatible with the DC Council's desire to ensure equitable business opportunities. For political leaders, auctions are often difficult marketplace policies to support, especially when a majority of small businesses operate alongside well-funded corporate competitors. Despite its economic efficiency, auctioning public parking through a traditional or Vickrey format to the highest bidder was and remains unpalatable to many officials for distributional equity reasons. Well-resourced food trucks or brickand-mortar restaurants with mobile extensions can exert power in auctions by outbidding lesser-resourced competition. In Washington, DC, a majority of Class A food truck licenses are held by single-truck, "mom-andpop" vendors (Parker, pers. comm.). An auction could favor more economically advantaged owners, spelling political disequilibrium for the District, as smaller vendors with limited access to capital would be unable to pay what would otherwise be their highest private value for the parking spot. Moreover, the time and effort required to create a responsive and complex auction system for all participants represents an expensive and possibly indefensible administrative cost that District officials were unwilling to assume. Thus, because of its political infeasibility, using an auction was not a realistic alternative despite its economic advantages.

DC officials also considered allocating public parking rights to food trucks via a random lottery system. A lottery delivers random outcomes 
and stands as a recognized chance mechanism. It has wide use in many societal contexts, and drawing lots oftentimes presents the fairest distribution of duties or rewards (Fienberg 1971). During the 30 years preceding the District's new mobile vending regulations, officials occasionally employed lotteries to grant sidewalk vending locations amid what many observers agreed was a broken mobile vending program (DC BCRA 2013). Fienberg (1971) writes that lotteries' attractiveness lies in their fair allocation of resources, and it was this characteristic that DC officials most wanted to emphasize in their attempt to update the District's out-of-date vending laws.

For regulators, developing a transparent, legitimate and valid allocation system has always been an important, if not hard-to-achieve, baseline characteristic in any vending solution (Parker, pers. comm.). During Washington, DC's 2013 mobile vending hearings, policy experts and food truck leaders expressed concern that, given the varying value vendors place on different parking spots, a pure lottery system would result in big winners and big losers. A few trucks would win one of a handful of prizes, namely constant-revenue locations, while the remaining trucks would win parking in lesser-established areas. Additionally, local business leaders expressed concern that any system created to allocate public parking to mobile vendors should not deliver "chance" results. The reason vendors claim chance cannot be a business strategy is because food trucks attempt to maximize revenue by strategically targeting certain parking spots based upon supply and demand and various contextual factors like weather, day of the week, and time of year (Trocchio et al. 2014). As a result, chance, to food truck vendors, is not a viable business method (Povich and Ruddell-Tabisola, pers. comm.). Vending advocates argued that a pure lottery, without any dynamic adjustments to its random outcomes, could not accommodate the demands of a constantly moving food truck scene, where trucks value flexibility to gauge the market, move and meet changing demands, and mitigate competition with similar cuisine providers.

The District's resultant policy is a hybrid solution. The lottery-rotation system is neither a pure lottery nor an auction. Despite its employment of a random number generator that begins the parking assignment process, its output is part chance and part equitable intervention by DCRA officials. The resulting monthly food truck rotations are a combination of random allocations created by an algorithm and officials' efforts in accordance with established guidelines to reconcile unexpected inequities. The main strength of Washington, DC's food truck policy is that the lottery is optional and roaming under established rules remains legal. This has the advantage of providing both guaranteed and flexible parking to vendors. If participating vendors want the promise of revenues in proven high-traffic areas, they may enter the lottery for a nominal fee and, if they like the results, accept them. Alternatively, not all popular vending locations within and outside of Washington, DC's Central Vending Zone are allocated by lottery each month. If vendors do not want to commit to a chance parking assignment in the lottery, they do not have to enter it to vend. They may roam at their own discretion and generate consumer interest via social media.

We conclude that the resultant system, at the time of its implementation, resembled a feasible policy 
solution that delivers social gains in a manner defined by Oliver E. Williamson's (2010) remediableness criterion. Williamson defined as efficient "an extant mode of organization for which no superior feasible form of organization can be described and implemented with expected net gains" (Williamson 1996). At the time of its passage, the policy was the most appropriate, most efficient, and best implementable choice. Over a year later though, food trucks have reacted to the District's new guidelines and the marketplace has changed. We recommend improvements that might bring DC's policy solution closer to regaining its earlier remediableness criterion.

The randomness plus equalaccess characteristics of Washington, DC's model make it a palatable answer to business owners and regulators alike. The consequences of this policy, however, are that District revenue is not maximized, and parking utilization is lower than it would be without existing constraints on political feasibility. There is no penalty for non-use of an assigned space. Moreover, no vendor can opportunistically seize unused MRV parking because doing so is illegal. An auction, despite being a political non-starter, would likely have ensured greater utilization of parking zones. In interviews with city officials, they also noted that the negative outcome of the lottery-rotation system is that it does not necessarily assure officials that the parking spots assigned will be used. We cannot conclude, therefore, that the lottery-rotation mechanism delivers Pareto efficiency such that no vendor can be made better off without making another vendor worse off. Despite the mechanism's rotational concept, which makes areas with high foot traffic reasonably and equally accessible to all market entrants and seems to deliver the transparency first envisioned by policymakers, the system does not fully exhaust the possibilities for gains from trade.

While truck vendors are allowed to trade parking permits with each other currently, they require DCRA to approve them. Despite the fact that DCRA approved 54 out of 56 trade requests made by email between September 23, 2014 and October 23, 2014 (Parker, pers. comm.), our study of October 2014's lottery zones, which included the most desirable vending locations, revealed that the MRV vacancy rate was still 64 percent (Trocchio et al. 2014). These vacancies and the unneeded administrative oversight costs to refill them indicate there is cause for policy change. Vendors' survey feedback, suggesting their dissatisfaction with unclaimed lottery assignments, further demonstrates the need to allow them greater flexibility to adjust their plans and gain approval at a moment's notice to accommodate unforeseen circumstances like truck mechanical malfunctions, employee absences, and inclement weather (Trocchio et al. 2014). Without the lottery-rotation system's ability to allow ad hoc vendor adjustments, the regulations require officials to constantly reassign private rights over parking to minimize losses. Incorporating a secondary market allowing vendors to actively trade parking permits among themselves represents what we believe is a relatively small adjustment posing significant gains toward attaining a new remediableness. In doing so, Washington, DC's mobile vending program could provide even greater flexibility and lower MRV zone parking vacancies. The change to allow a post-assignment trading scheme would increase social surplus for vendors, increase the attractiveness of MRV zone parking, decrease admin- 
istrative costs, and ultimately more closely resemble the more efficient allocation results of an auction.

In a related policy adjustment, officials are now considering changes to the price vendors pay to accept their MRV lottery assignments. At present, vendors rarely earn an MRV assignment every day of the week because the number of lottery entrants each month outnumbers the available parking spots contained within the lottery. As a result, some have suggested that instead of paying the $\$ 25$ entry fee plus a fixed $\$ 150$ monthly fee to earn anywhere between one to five days of guaranteed vending, vendors should pay the entry fee, plus a monthly fee of $\$ 30$ times the number of days earned per week. For example, if a vendor earns three days of vending per week, they would only pay a $\$ 90$ monthly fee, instead of $\$ 150$.

We contend, however, that further lowering the price to vend in an MRV lottery zone through this proration scheme would attract more trucks to participate in the system. Doing so would lower the odds of any given truck being assigned to one of the three most desirable MRV zones, Metro Center, Farragut Square, or L'Enfant Plaza, which is the reason why most trucks compete in the lottery in the first place (Trocchio et al. 2014). The larger issue at hand, though, is the further devaluation of prime real estate, which further exacerbates the aforementioned commons problem and the associated degradation of this public-use space. This policy would intensify these problems because it lowers the price of valuable real estate, effectively subjecting it further to the problems connected to its non-excludability.

While we acknowledge the political infeasibility of raising the price of parking, maintaining the status quo price of the lottery is better than any policy that lowers it. The system's higher-than-expected vacancy rates and the comparable $\$ 10,000$ to $\$ 15,000$ monthly lease fees that brick-and-mortar restaurants pay (Brannon 2015) suggest that the marginal cost of participating in the lottery is much lower than the marginal revenue participants earn. Vendors understand the high level of sales possible at the previously noted three most popular MRV zones. In October 2014, vendors were willing to pay $\$ 175$ for a 34 percent chance of winning parking in one of these zones that could deliver sales amounting to over \$1,500 in four hours (Trocchio et al. 2014). Despite the fact that fee proration was the dominant suggestion for improvement by a majority of surveyed vendors (Trocchio et al. 2014), we predict that a policy change to prorate acceptance fees would do very little to address the District's concerns about MRV zone vacancy and accountability connected to unused MRV assignments. The price to enter the lottery and earn MRV zone parking is already too low. Until the marginal cost of lottery participation rises to the level of marginal revenues earned, the chances for winning the most highly desired lottery parking will remain low. Further, MRV occupancy rates across all lottery zones will remain persistently high.

In lieu of fee proration, DC officials could consider other adjustments to increase the utility derived from MRV parking. October 2014's high vacancy rate suggests that the monthly lottery rotation may include too many MRV zones. Opening these zones to roaming food trucks or allowing their trade on a secondary market as described previously might increase their utilization. Other possible actions include limiting the number of lottery entrants or penalizing a 
truck for not using its spot, as is done in Boston's lottery, suggest Peter Murphy and Tara Hatala of the Mayor's Office of Food Initiatives in Boston (pers. comm.). Further, DC might consider installing smart parking meters, as was done in Las Vegas' food truck parking zones, allowing officials to track vendors' parking spot use and adjust the rates they pay compared to regular automobiles. Segregating lottery vendors by menu type might also help because when trucks see an overabundance of similar menu selections assigned to one MRV zone, some do not show up to compete. Regardless of the methods DC officials take to improve the regulations, the lottery's parking guarantee and its ability to limit negative parking behaviors remain its core strengths.

\section{Conclusion}

Washington, DC's food truck policy represents a compromise between doing what is optimal and doing what is possible. It is a nextgeneration, low-cost marketplace solution that foregoes Pareto efficiency for feasibility, providing low barriers to entry and relatively minimal administrative costs. In this way, it is a long-overdue political and economic win for regulators and vendors. City administrators who attempt to disentangle politics and policy, in the belief that by doing so somehow the public will be better off, will almost certainly encounter failure: good policy not only should but must make good political sense. As widely-cited economists and political scientists Daron Acemoğlu and James A. Robinson (2013) note in an article describing the pitfalls of using economics to make policy recommendations, good economics equates to bad politics if regulators fail to understand where the two arenas conflict. Markets with strong, organized interest groups encourage politicians to take regulatory action - or to not take regulatory action if that is what the organized interests prefer-to stay in office. Despite its inefficiencies, the District's action strikes the right economic and political balance under current conditions.

Though we suggest minor policy adjustments to account for marketplace changes, as a whole, DC's food truck policy does not unnecessarily give advantage to any particular interest group that, in a future administration, might be empowered to upset the political equilibrium found at present. As Acemoğlu and Robinson (2013) further describe, policymakers should be concerned with future political equilibria when they draft present-day laws that involve minority and majority interest groups. Washington, DC's new food truck policy seems reasonably balanced to be an enduring, equitable solution for all stakeholders.

Prior to implementing the lottery program, DC council members faced intense public backlash when they first published rules on vending business license regulations. Local and national restaurant associations and the DMV FTA petitioned Washington, DC's leadership from the outset to create equitable, clearly worded regulations that preserved each group's capital interests. Brickand-mortar operators contended that their restaurants' overhead costs put them at a disadvantage relative to their mobile competition - an argument bolstered by the claim that city governments that guarantee parking to food trucks implicitly subsidize their operations (Epstein 1994). Food truck advocates pointed out that the food truck regulations first proposed would prohibit food trucks from operating in eight square blocks of Washington, DC's prime mobile 
vending locations (DC BCRA 2013). After years of hearings and public comment periods, officials began to recognize how a pure lottery's "chance" outcomes could not accommodate this dynamic market, and how an auction might favor a wealthy minority segment of owners. For food trucks and restaurants to coexist, DC policymakers have rightly considered the politics of their environment in driving toward a solution.

In the end, food truck vending regulations represent an excellent example of how important compromise is to good policymaking. The sophisticated tastes of Facebook- and Twitter-savvy diners demand that vendors remain agile in a dynamicbut-often-restricted urban environment. District officials, in response, wisely make political and economic choices to preserve the industry and allocate valuable common resources-in the most efficient manner that is feasible-while ensuring public safety and access to parking.

In the 18 months since its inception, Washington, DC's lotteryrotation system has matured only enough to present us with an introductory mobile cuisine heat map of sorts, depicting vendor preference for
MRV zones and parking utility spanning just over one annual vending season. The lottery-rotation system represents a promising beginning to understanding the market better and for collecting and studying long term mobile vending activity. Washington, DC's approach to this common resource challenge is a feasible answer to managing food truck parking, despite evidence that it may not maximize parking utilization. As the policy is tested and the market matures, regulatory adjustments must be informed by vendor preference and behavior. Knowing more about what MRV zones are preferred when-and by whom-will help policymakers do this. A secondary market is an important step toward increasing flexibility and maximizing the use of available parking. Installing advanced or "smart" street meters to vary parking prices in accordance with demand would help better reflect and ensure care of DC's valuable curbside real estate. Regardless of the inevitable system changes that are proposed, we look forward to watching politicians, policy analysts, and stakeholders continue to work together toward implementing the best solution possible within the realm of what is feasible.

\section{References}

Acemoğlu, Daron, and James A. Robinson. 2013. “Economics Versus Politics: Pitfalls of Policy Advice." Journal of Economic Perspectives 27(2):173-92.

"Americans and Their Cars: The Race for Space." 2015. The Economist, January 10. Accessed February 22, 2015. http:/ / www.economist.com/ news / united-states / 21638132-free-parking-not-all-its-cracked-upbe-race-space.

Blanche, Bruce L. 2014. "Report of Special Evaluation. Parking and Automated Traffic Enforcement Tickets - Part I: Ticket Issuance Practices." Washington, DC: Office of the Inspector General. Accessed March 6, 2015. http: / / oig.dc.gov/ release/ report-special-evaluation-parking-andautomated-traffic-enforcement-tickets-part-i-ticket.

Brannon, Ike. 2015. “The Food Truck Farce.” The Weekly Standard, February 4. Accessed March 1. http: / / www.weeklystandard.com/blogs / food- 
truck-farce_837954.html.

Carman, Tim. 2012a. "New Regulations Proposed for DC Food Trucks." The Washington Post, October 5. Accessed February 10, 2015. http: / / www. washingtonpost.com/local/dc-issues-new-vending-regulations-forfood-trucks / 2012 / 10/05 / 81c2e13a-0eee-11e2-bd1a-b868e65d57eb_story.html.

2012b. "Regs Would Limit Food Trucks in Downtown DC." The Washington Post, November 8. Accessed February 10, 2015. http: / /www. washingtonpost.com/blogs/all-we-can-eat/ post/ regs-would-limitfood-trucks-in-downtown-dc / 2012/11 / 08 / 86eb83ec-2910-11e2-bab2eda299503684_blog.html.

CBO (Congressional Budget Office). 1992. "A CBO Study: Auctioning Radio Spectrum Licenses." Washington, DC: Congressional Budget Office.

DC BCRA (Council of the District of Columbia Committee on Business, Consumer, and Regulatory Affairs). 2013. “Draft Committee Report on Proposed Resolution 20-0125: Vending Business License Disapproval Regulation Resolution of 2013." Washington, DC: Committee on Business, Consumer, and Regulatory Affairs. Accessed February 7, 2015. http:/ / www.documentcloud.org/documents/705889-draft-committeereport-vending-regs.html.

DC PSCA (Council of the District of Columbia Committee on Public Services and Consumer Affairs). 2009. "Bill 18-257, the 'Vending Regulation Act of 2009.'" Washington, DC: Committee on Public Services and Consumer Affairs. Accessed March 9, 2015. http:/ / dcclims1.dccouncil.us / images / $00001 / 20090827155702$.pdf.

DCRA (Department of Consumer and Regulatory Affairs). 2013. “Central Vending Zone." Washington, DC: Department of Consumer and Regulatory Affairs.

2014. "Redacted List of Class A Licensees." Washington, DC: The Department of Consumer and Regulatory Affairs.

2015a. "Central Vending Zone." Washington, DC: Department of Consumer and Regulatory Affairs. Accessed April 6. http:/ / dcra.dc.gov / sites/default/files/dc/sites/dcra/publication/attachments/Central_ Vending_Zone.pdf.

2015b. "Get a Vending License." Washington, DC: Department of Consumer and Regulatory Affairs.

DDOT (District Department of Transportation). 2013. "Meter Rates and Hours of Operation." Washington, DC: Department of Transportation. Accessed December 1, 2013. http: / /ddot.dc.gov/ service/parking-meters. http:/ / dcclims1.dccouncil.us/images/00001/20090827155702.pdf.

DMV FTA (District of Columbia, Maryland, and Virginia Food Truck Association). 2014. "Our Story." Accessed February 10, 2015, http:/ / www. dmvfta.org/whoswho\# ourstory.

Easley, David, and Jon Kleinberg. 2010. Networks, Crowds, and Markets: Reasoning About a Highly Connected World. New York: Cambridge University Press.

Epstein, Richard. 1994. "The Informal Economy: The Moral and Practical Dilemmas of an Underground Economy." Yale Law Journal 103(8):2157-77.

Farrell, George. 2013. “DC City Council Debates Food Truck Regulations Today." Washington Times, May 10. Accessed February 7, 2015. 
Policy Perspectives | Volume 22

Fienberg, Stephen E. 1971. "Randomization and Social Affairs: The 1970 Draft Lottery." Science 171(3968):255-61. Accessed February 28, 2015. http:/ / classes.engr.oregonstate.edu / cbee / spring2013 / cbee213-001 / Labs / ScienceDraftPaper.pdf.

"Food Truck Proposal Map." 2013. The Washington Post, May 10. Accessed April 6, 2015. http: / / www.washingtonpost.com/lifestyle/food/foodtruck-proposal / 2013/05/10/4e20727c-b9c8-11e2-92f3-f291801936b8_ graphic.html.

Hardin, Garrett. 1968. "The Tragedy of the Commons." Science 162(3859):1243-48. Accessed February 28, 2015. http: / / www.jstor.org / stable/1724745?origin=JSTOR-pdf.http://www.jstor.org/ stable/1724745?origin=JSTOR-pdf

Intuit. 2012. "Food Trucks Motor Into The Mainstream." Accessed November 28, 2012. http: / / network.intuit.com/wp-content/uploads / 2012/12 / Intuit-Food-Trucks-Report.pdf.http://network.intuit.com/wp-content/ uploads/2012/12/Intuit-Food-Trucks-Report.pdf

Johnson, Kyle. 2013. "Food Truck Association Responds to Proposed Regulations." Accessed April 7, 2015. http: / / foodtruckfiesta.com / food-truckassociation-responds-to-proposed-regulations / .

Neu, Ryan. 2013. “Washington D.C. Tops the Charts with $\$ 159$ of Parking Ticket Revenue Per Citizen." Parking Today, December 19. Accessed November 15, 2014. http: / / www.parkingtoday.com/blog/2013/12/ washington-d-c-tops-the-charts-with-159-of-parking-ticket-revenueper-citizen/.

Parker, Vincent. 2013. "Mobile Roadway Vending (MRV) Training." PowerPoint slideshow presented to the Department of Consumer and Regulatory Affairs, Washington, DC, November 22.

Trocchio, Clint, Dilyana Watts, Arwen Lin Sun, and Drew Todrys. 2014. “An Analysis of Mobile Vending Behavior of Food Trucks Participating in Washington, DC's Mobile Roadway Vehicle (MRV) Vending Lottery System." MPA Capstone, The George Washington University.

Williamson, Oliver E. 2010. "Transaction Cost Economics: The Natural Progression." American Economic Review 100(3):673-690.

1996. The Mechanisms of Governance. Oxford: Oxford University Press.

Commander Clint Trocchio is an 18-year Coast Guard Officer and Naval Aviator hailing from Ravenna, Ohio. He holds a Bachelor of Science from the US Coast Guard Academy, a Master of Business Administration from Spring Hill College, and most recently a Master of Public Administration from the George Washington University's Trachtenberg School. Commander Trocchio is currently assigned as a detailee to the US Senate Committee on Appropriations. $\mathrm{He}$ is a Big Brother mentor, a volunteer at Miriam's Kitchen in Washington, DC, and a crossword puzzle fanatic. When the waves are up, he surfs.

Lieutenant Paul J. Miller of the US Coast Guard is from Northern Virginia and currently assigned to Coast Guard Congressional Affairs in Washington, DC. He also holds a Bachelor of Science in Mechanical Engineering from the US Coast Guard Academy, a Master of Business Administration from Okla- 
homa State University, and a Master of Public Administration from the George Washington University. Paul has served as the Commanding Officer of the Coast Guard Cutter Halibut, home ported in Marina del Rey, California, and the Coast Guard Cutter Pea Island, home ported in Key West, Florida. In addition, he served as aide-de-camp to the Chief of Staff of the Coast Guard in Washington, DC, and as an Operational Planner at the Joint Interagency Task Force South in Key West, Florida, a component of US Southern Command. In his off time, Paul volunteers as a Hometown Mentor with the College Success Foundation for a Washington, DC, high-school student.

The authors first thank Vincent Parker from Washington, DC's Department of Consumer and Regulatory Affairs for contributing to this study and for his service to Washington, DC's mobile vending community. We also thank Doug Povich, Che Ruddell-Tabisola, and Karen Wrege from the District of Columbia, Maryland, and Virginia Food Truck Association; Matt Geller from the Southern California Mobile Food Vendors Association; Brett Tarnutzer from the Federal Communications Commission; and Dr. John Gaber from the University of Arkansas. We offer thanks to the mobile vending program coordinators from Boston, Las Vegas, and Seattle for sharing insights about their cities' vending programs. We recognize the wonderful editing and counsel from our editors at Policy Perspectives and from our faculty advisor, Dr. Christopher Carrigan. We give particular thanks to our families, who for years endured our time away from home with patience and love. And lastly, we recognize the savvy, committed food truck vendors in Washington, DC, who contributed to this study and who make the District's urban eating scene so vibrant and special. 